\title{
Review of the Effect of Climatic Conditions to the Development of Erosion Process in Soils of Azerbaijan
}

\section{RAE Aliyev ZH*}

Institute of Soil Science and Agrochemistry of ANAS, Azerbaijan

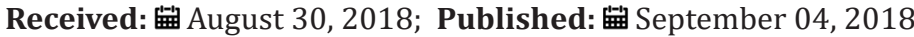

*Corresponding author: RAE Aliyev ZH, Institute of Soil Science and Agrochemistry of ANAS, Baku, Azerbaijan

\begin{abstract}
The Researchers proved that the process of soil erosion is also closely linked to climatic conditions of the region. Therefore, depending on the climatic conditions of the erosive processes are different in both forms of its manifestation, and the quantitative indicators of development. For example, in the north-eastern part of the Greater Caucasus Highlands powerful deposition of snow cover, high intensity of spring melting of snow and summer rain water rainfalls the calling intensive lavages and size of its development areas. But here, against a backdrop of high air temperatures during the growing season, pronounced wind regime and extremely low relative humidity of the air is wind erosion. Climate also affects the surface configuration. Humid areas where vegetation cover protects the soil from severe manifestations of water and wind erosion, characterized by soft, rounded slopes.
\end{abstract}

Keywords: Climate; Soil; Erosion; Infiltration

Introduction (Figure 1)

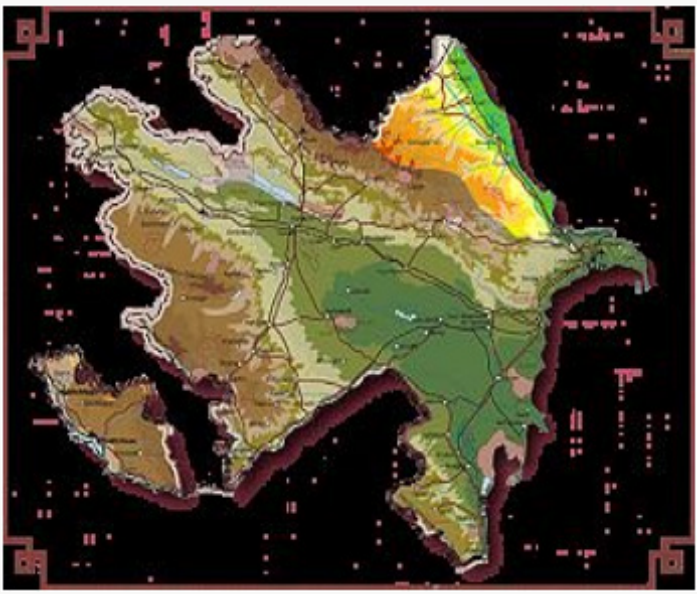

Figure 1: Map of erosion risk soils of Azerbaijan.

Soil erosion is an ongoing process, which consists in moving soil mass from one place to another, under the influence of water, wind and gravity [1]. Among the numerous classifications, organize my erosive phenomenon, the most important is the separation of erosion: natural (caused by forces of nature) and accelerated (caused by human activities). Erosion processes caused by forces of nature (wind, water and gravity erosion), the largest scale in a glacial period when the vegetation was negligible. The emergence of higher (herbaceous and woody) plants heavily restricted and even helped to overcome the action of erosion processes, accelerate soil formation processes and soil formation [1,3]. Human activities (agriculture (agronomy) erosion) is the main factor which contributes to development and an increase in the intensity of erosion processes, collapsing the Earth's mainland surface, which led to the significant in terms of size, soil degradation, reducing, and even destruction of its productive capacity, compared with natural conditions [2].

\section{Progress in the Study and Discussion of Materials}

(Economic), from a practical point of view stands out-a potential erosion described as erosion risk and actual (current) erosion, described as erosive damage in mostly size floating soil masses (in $\mathrm{mm}$ thickness or $\mathrm{t} / \mathrm{ha}$ or $\mathrm{km}^{2}$ ). Along with that, in areas with dry climates where the water flows very fast and where the wind taking sand particles and working them as cutter, erases the surface and sweeps weathering products typical of sharply defined overskirt. When examining the erosion problem is extremely important to identify leading factors and establish their relevance to the 
erosive process. Such determinant nature of erosion is primarily precipitation, then wind regime [3]. Development intensity of erosion processes is defined not only in terms of average annual precipitation in the area, but also to a large extent, their intensity. If most of the annual rainfall mean weak or moderate falling rain, moisture is absorbed into the soil without runoff and erosion, favorable conditions for snow water absorption of small runoff and erosion of underdevelopment is created and, if large part of rainfall on soil nonfreezing or motion enough snow limits the freezing it $[2,5]$. With little snow cover and the same deep frost heave soil warm spring rains can cause increased melting of snow, strong stock and sharply expressed by erosion. Of equal importance is the distribution of rainfall in time. Particularly unfavorable for erosion control is a long, albeit moderate intensity falling rain and extremely intense intermittent showers. The first type of falling rain soil, sated after some time in the future moisture absorbs it very slowly, with the result that the run off and surface erosion are amplified When intense. showers water enters the soil surface so fast that even structural, drained soil doesn't absorb increases it, resulting in the formation of enhanced runoff and erosion. Especially destructive processes of storm runoff and washing, where vegetation, slopes, even from much permeability of soils do not protect $[2,3]$. Pounding raindrops in this case crush soil (semi arid and arid regions) aggregates and form on the soil surface rather ton, razzhizhennuju mud, which clogs the pores of the infiltration process and drastically weakens the absorption of moisture. This in turn reinforces the excessively drain and erosion even on light soils.

On the surface of the chilled soil flushing processes are absent. But the freezing and thawing of the soil the timephased cause slipping its particles and even washed away down the slope.These processes of sliding and soil flushing occur particularly intensively in cases where spring temperatures accompanied by warm rains. Rains causing it to thawing the soil, often wash off all its surface layer.The erosion caused by rain and heavy waters, exposure conditions affected to a much lesser extent. The wind is also a very important and active agent of erosion, which is widely published in the form of wind erosion, exclusively inherent in semi-arid and arid regions, although only to the extent that this factor is the most dramatic [3,5]. In essence, the same uncoated soil surface depends to a greater or lesser degree on the distorting effect of wind flowing all over the world, even in wet areas. Under the influence of a blatant and smoothening (winding) wind vortex, the soil particles rise into the air and larger moving rolling elements either in jumps and boundaries and precipitate to form deposits in the form of spit, ridges or dunes, the risk of wind erosion especially increases the dryness of the weather in spring $[2,6]$.

\section{References}

1. Aliev BH, Aliev ZH (2001) Zoning of the territory of Azerbaijan Republic on choosing advanced irrigation techniques. Monograph, Publishing house "Ziya” Baku pp. 297.

2. Aliev BH, Aliev ZH (2000) Erosion in Azerbaijan and ways of its solution. Ziya-CPI, Naji Baku pp. 122.

3. Aliev ZH (2007) The premises about the most important problem of the agriculture in water resource provision mountain and foothill regions of Azerbaijan. JAA 1(3): 179-182.

4. (1985) Central Scientific agricultural library ALL the soil erosion and control. Moscow.

5. MN Bagrov, IP Circlin (1985) Agricultural land Reclamation. Moscow.

6. M Sousse (1989) Soil erosion and control. Moscow.

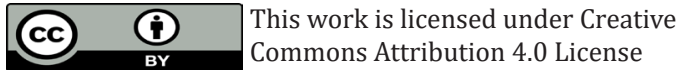

To Submit Your Article Click Here: Submit Article

DOI: $10.32474 /$ OAJESS.2018.01.000109

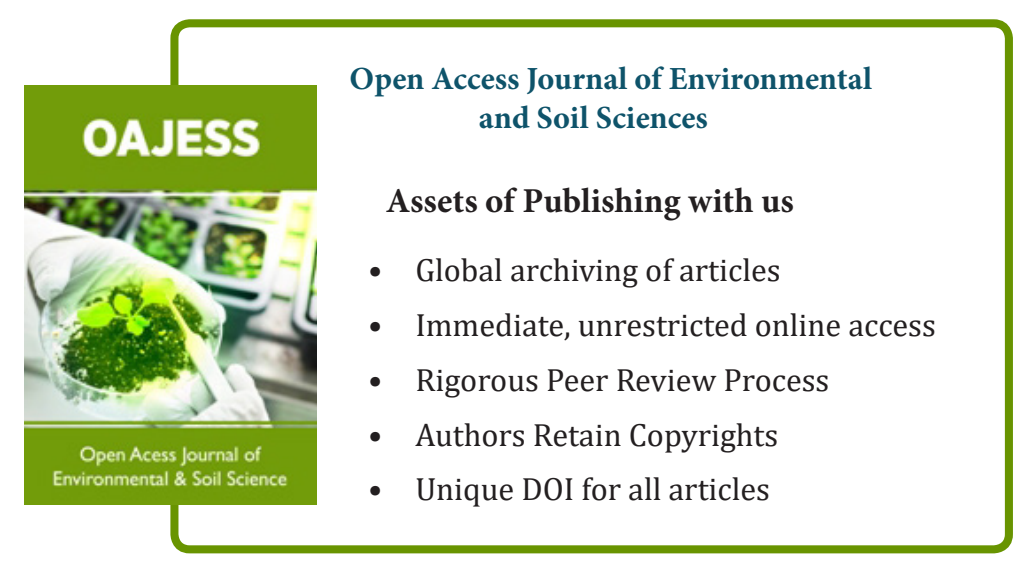

